\title{
A Early Development of Severe Ovarian Hyperstimulation Syndrome following Ovulation Induction
}

\author{
Fayaz Ahmad Sofi, M.D., Wasim Ahmed, M.D., Ghulam Nabi Dhobi, M.D., Showkat Ali Mufti, M.D., \\ Rafi Ahmed Jan, M.D., Shaheen Nazir Lone, M.D., Bashir Ahmed Shah, M.D. \\ Department of Internal Medicine, Sher-i-Kashmir Institute of Medical Sciences, Srinagar Kashmir, J\&K (India)
}

\section{A B S T R A C T}

Ovarian Hyperstimulation is a rare but potentially fatal complication of ovarian stimulation during treatment of infertility. Worldwide the incidence of this syndrome is increasing due to liberal use of invitro fertilization for management of infertility. The syndrome is characterized by cystic ovarian enlargement and abnormal capillary permeability due to secretion of vasogenic substances by ovaries. The syndrome is classified into early and late variants with early variants usually mild to moderate in severity. We present a case of severe ovarian hyperstimulation syndrome (OHSS) developing early in a 25-year female while undergoing In-vitro fertilization (IVF). Six days after ovulation induction, the woman developed ascites, bilateral pleural effusion and acute renal failure with ultrasound abdomen revealing bilateral cystic enlargement of ovaries. JMS $2011 ; 14(1): 30-32$

Key words: Ovarian hyperstimulation, ovulation induction, in-vitro fertilization, IVF

OHSS is an iatrogenic complication of the luteal phase and/or early pregnancy after ovulation induction (provoking ovulation in anovulatory women) or of ovarian stimulation (in the context of intrauterine insemination or in vitro fertilisation). It ranges in severity from mild self limiting illness to a potentially fatal one. The pathophysiological hallmarks of the syndrome are cystic enlargement of the ovaries and abnormal capillary permeability resulting in third space fluid loss. Treatment is largely supportive with emphasis on adequate fluid resuscitation. Though Early OHSS is usually mild we report a case of 25 year old Female who developed Severe OHSS within one week of ovulation induction while undergoing In-vitro fertilization (IVF) with Embryo Transfer on account of oligospermia in her husband.

\footnotetext{
Correspondence and reprint requests to:

Dr. Fayaz A Sofi

Department of Internal Medicine,

Sher-i-Kashmir Institute of Medical Sciences, Srinagar, Kashmir (J\&K) India - 190011

Email:fayazkanjwal@rediffmail.com
}

\section{Material and Methods}

A 25 years old Female with insignificant medical history in the past underwent IVF with Embryo Transfer after her husband was found to have Oligospermia. Patient initially received Gonadotropin Releasing Hormone (GnRH) analogue for downregulation of Pituitary function followed by Recombinant Follicle Stimulation Syndrome (rFSH) for ovarian stimulation that was followed by Human Chorionic Gonadotropin (HCG) for ovulation induction. Six days after receiving HCG patient developed abdominal discomfort and distention. One day later patient developed breathlessness and had decreased urine output and was admitted in our hospital. On examination patient was conscious with apparent respiratory distress, had a pulse of 118 per minute and Blood Pressure of 80/50 mmHg. She had clinical signs of Bilateral Pleural effusion and Ascites. Rest of the clinical examination was unremarkable.

Investigations revealed leucocytosis of $18,800 / \mathrm{mm}^{3}$ with 90\% neutrophills. Blood Urea was $104 \mathrm{mg} / \mathrm{dl}$ and Serum creatinine $2.2 \mathrm{mg} / \mathrm{dl}$. Liver Function Tests revealed raised AST and ALT of $117 \mathrm{mg} / \mathrm{dl}$ and $155 \mathrm{mg} / \mathrm{dl}$ respectively with low albumin levels of $2.3 \mathrm{mg} / \mathrm{dl}$. Urine examination was normal. 
ECG revealed Sinus Tachycardia. X-Ray chest was suggestive of Bilateral Pleural Effusion. Ultrasound Abdomen [Figures 1-3] was reported as massive ascites with bilateral enlargement of ovaries with multiple cystic areas of varying sizes. Volumes of Right and Left ovaries were 480 and $450 \mathrm{ml}$ respectively. Ascitic Fluid analysis revealed a cell count of $200 / \mathrm{ccm}$ with $92 \%$ Lymphocytes, Proteins of $5.3 \mathrm{gm} / \mathrm{dl}$ and Albumin $1.8 \mathrm{mg} / \mathrm{dl}$.

Patient was diagnosed as Ovarian Hyperstimulation Syndrome, Severe Grade 4 as per Golan's Severity criteria (Table 1). She was managed with Intravenous Fluids (Normal Saline) with regular monitoring of vitals. Supplemental Oxygen was given and Therapeutic Thoracentesis was done in view of respiratory distress. Prophylactic Heparin (Unfractionated) was given to prevent any thrombotic complication. Patient showed improvement after two days of treatment. Her Blood Pressure

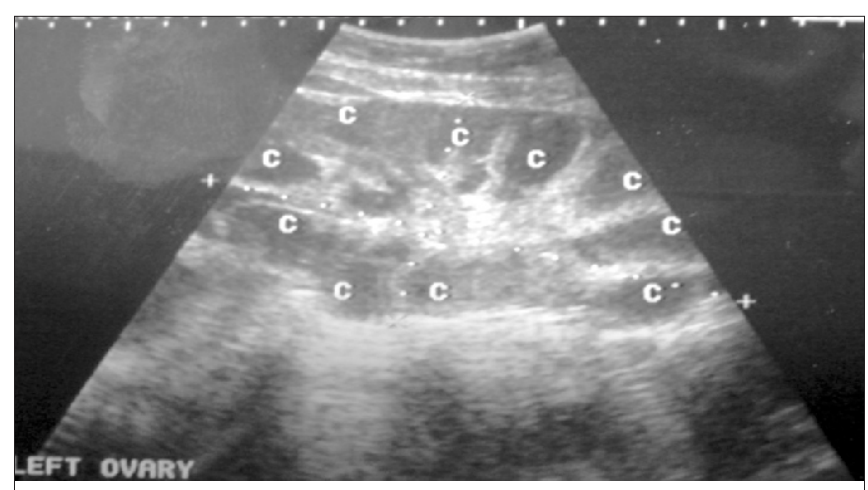

FIGURE 1: USG Abdomen showing Enlarged Left Ovary with Multiple cystic spaces

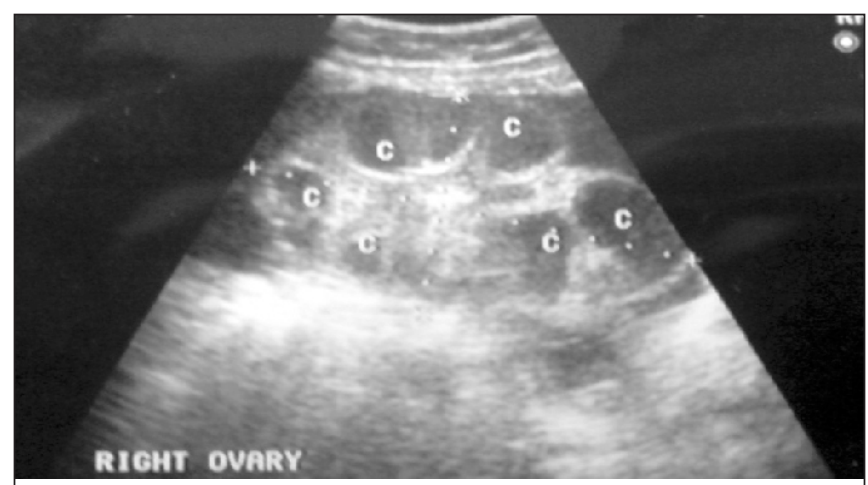

FIGURE 2: USG Abdomen showing Enlarged Right Ovary with Multiple cystic spaces.

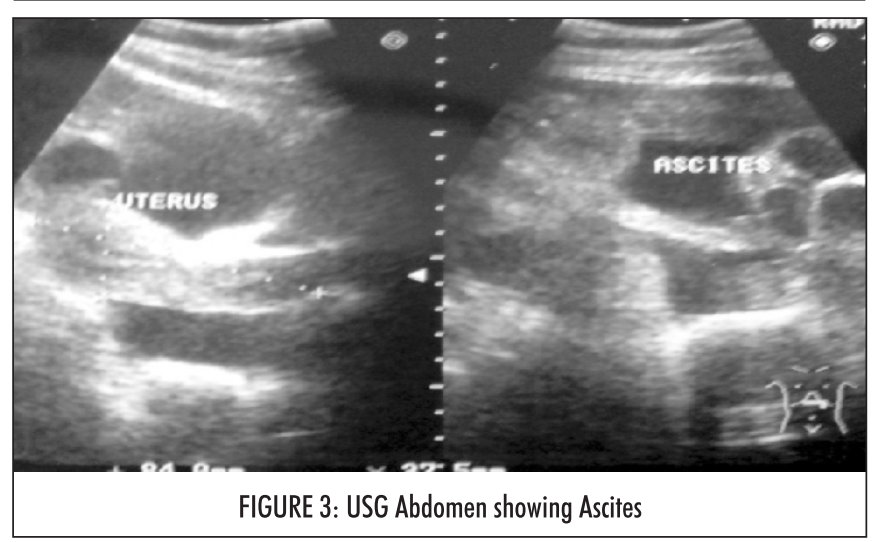

Table 1: Golan's Severity Scoring in OHSSI4

\begin{tabular}{lll}
$\begin{array}{l}\text { Grade of } \\
\text { OHSS }\end{array}$ & \multicolumn{1}{c}{ Mild } & \multicolumn{1}{c}{ Severe } \\
\hline $\begin{array}{l}\text { 1. } \\
\text { Abdominal } \\
\text { distention and } \\
\text { discomfort }\end{array}$ & & \\
\hline 2. & $\begin{array}{l}\text { Criteria of grade 1 } \\
\text { plus nausea, vomiting, } \\
\text { and/or diarrhea. Ovaries } \\
\text { enlarged 5-12 cm }\end{array}$ & \\
\hline 3. & $\begin{array}{l}\text { Criteria of mild OHSS plus } \\
\text { echographic signs of ascites }\end{array}$ \\
\hline 4. & $\begin{array}{l}\text { Criteria of moderate OHSS } \\
\text { plus clinical signs of ascites } \\
\text { and/or hydrothorax and } \\
\text { respiratory distress }\end{array}$ \\
\hline 5. & $\begin{array}{l}\text { All of the above plus changes } \\
\text { in blood volume and viscosity, } \\
\text { hemoconcentration, } \\
\text { Coagulation disorders, and } \\
\text { decreased renal output and } \\
\text { function }\end{array}$ \\
\hline 6. & \begin{tabular}{l} 
Life threatening form \\
\hline
\end{tabular} &
\end{tabular}

stabilized with fluid resuscitation. Respiratory distress settled. Abdominal Girth decreased from $109 \mathrm{~cm}$ to $92 \mathrm{~cm}$ and weight decreased from $67 \mathrm{Kg}$ to $53 \mathrm{Kg}$ in six days. Patient menstruated on 6th day thereby ruling out pregnancy. Patient was discharged on 7th day after becoming asymptomatic and normalization of Renal Function Tests.

\section{Discussion}

OHSS is usually a complication of Assisted Reproduction Technology (ART) but can be rarely spontaneous. ${ }^{1}$ Familial cases of OHSS have been reported due to mutations in FSH receptor gene. ${ }^{2}$ The syndrome is caused by abnormal and excessive response of ovaries to stimulation during ART and its incidence is related to the stimulation regime used with a high incidence when Gonadotrophins are used. Moderate OHSS is seen in 8\% of stimulation cycles using clomiphene citrate. ${ }^{3}$ Worldwide the incidence of OHSS is increasing due to liberal use of IVF for management of infertility. ${ }^{4}$ A number of risk factors predispose the patients to development of OHSS (Box 1$){ }^{5}$

The two hallmarks of OHSS are Cystic enlargement of Ovaries and Secretion of Vasoactive substances especially Vascular Endothelial Growth Factor (VEGF) leading to abnormal capillary permeability with loss of Intravascular fluid into third space. ${ }^{6}$ OHSS is classified into Early and Late variants. Early OHSS occurs within 3 to 7 days after ovulation induction, is usually mild to moderate in severity and is caused by exogenous HCG. Late variant occurs after 10 days of ovulation, is usually severe and related to placental HCG secretion. The clinical features of OHSS are related to four Pathophysiological 


\section{Box 1: Risk Factors for Development of OHSS}

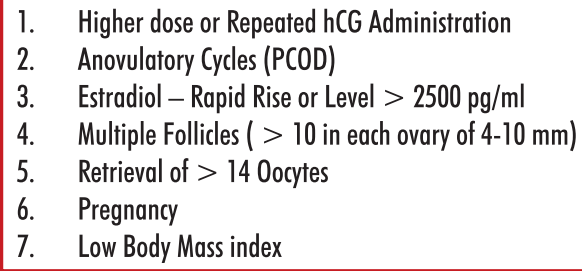

1. Higher dose or Repeated hCG Administration

2. Anovulatory Cycles (PCOD)

3. Estradiol - Rapid Rise or Level $>2500 \mathrm{pg} / \mathrm{ml}$

4. Multiple Follicles ( $>10$ in each ovary of $4-10 \mathrm{~mm}$ )

5. Retrieval of $>14$ Oocytes

6. Pregnancy

7. Low Body Mass index

mechanisms, 1) Ovarian enlargement, 2) Abnormal capillary permeability, 3) Hypercoagulablity, and 4) Decreased Ig A and Ig Glevels.

Ovarian enlargement causes abdominal discomfort, nausea, vomiting and bloating sensation. Abnormal capillary leakage causes third space fluid collection in the form of ascites, pleural or pericardial effusion. Severe loss of volume can lead to hypotension, shock and organ dysfunction due to tissue hypoperfusion. Hypercoagulablity in OHSS leads to both venous and arterial thrombosis and Pulmonary Thromboembolism has been described. ${ }^{7,8}$ Venous Thrombosis is remarkable for its predilection for veins of neck and upper limbs. Arterial Thrombosis usually involves the Cerebral vessels. Low levels of Immunoglobulins IgA and IgG predispose patients of OHSS to infections of which Urinary Tract infections are the most common. ${ }^{9}$

Laboratory data is characterized by hemoconcentration (Hct $>45 \%$ ) and raised white blood cell and platelet counts. ${ }^{10}$ Hyponatremia and Hyperkalemia may be seen. Abnormal liver function tests are seen in $30 \%$ of patients with OHSS. ${ }^{11}$ Hypoalbuminemia is universal. Raised serum creatinine points to severe OHSS. Low levels of IgA and IgG are seen in patients with severe OHSS and predisposes to infections. ${ }^{12}$ The plasma levels of renin, aldosterone, noradrenaline, antidiuretic hormone $[\mathrm{ADH}]$ and atrial natriuretic peptide $[\mathrm{ANP}]$ are increased. $^{10,12}$ Urinary sodium concentration is low in most patients. Ascitic fluid study reveals high protein and low cell counts. ${ }^{12}$ Complications of OHSS are Pulmonary Oedema, ARDS, DIC or Hepatic Dysfunction. Surgical complications include Ovarian Torsion, rupture and Haemorrhage.

Treatment of OHSS is largely supportive. Medical management is mainly to maintain circulatory function and prevent organ dysfunction. The intravascular volume should be maintained to prevent hemoconcentration and allow sufficient urine output. Initial fluid of choice is crystalloids. ${ }^{3}$ Intravascular volume expansion with dextran has been associated with development of ARDS in patients with OHSS. ${ }^{13}$ In patients with hematocrit more than $45 \%$ or hypoalbuminemia less than $30 \mathrm{gm} / \mathrm{L}$ or ascites, human albumin is the plasma expander of choice. In severe cases of OHSS prophylactic anticoagulation should be used. In presence of thromboembolism therapeutic anticoagulation is indicated. ${ }^{3,5}$

\section{Conclusion}

OHSS can be a severe complication of infertility treatment and fatalities have been reported. The affected patients are usually young females who otherwise have no significant illness and hence it is important for healthcare providers to be aware of its clinical features, complications and management to prevent its disastrous outcome. Management is largely supportive with emphasis on adequate fluid resuscitation and prevention of complications especially venous and arterial thrombosis.

\section{References}

1. Abu-Louz, SK, Ahmed AA, Swan RW. Spontaneous ovarian hyperstimulation syndrome with pregnancy. Am J Obstet Gynecol 1997; 177:476-477.

2. Vasseur C, Rodien P, Beau I, et al. A chorionic gonadotropinsensitive mutation in the follicle-stimulating hormone receptor as a cause of familial gestational spontaneous ovarian hyperstimulation syndrome. N Engl J Med 2003; 349:753-9.

3. Avecillas JF, Falcone T, Arroligo AC. Ovarian hyperstimulation syndrome. Crit Care Clin 2004;20: 679-95.

4. Abramov Y, Elchalal U, Schenker JG. An 'epidemic' of severe ovarian hyperstimulation syndrome: a price we have to pay? Hum Reprod 1999;14,:2181-2183.

5. Practice Committee of the American Society for Reproductive Medicine. Ovarian hyperstimulation syndrome. Fertil Steril 2004;82:S81-6.

6. Geva E, Jaffe RB. Role of vascular endothelial growth factor in ovarian physiology and pathology. Fertil Steril 2000; 74:429-38.

7. Stewart JA, Hamilton PJ, Murdoch AP. Thrombo-embolic disease associated with ovarian stimulation and assisted conception techniques. Hum Reprod 1997;12:2167-73.

8. Tavmergen E, Ozcakir HT, Levi R, et al. Bilateral jugular venous thromboembolism and pulmonary emboli in a patient with severe ovarian hyperstimulation syndrome. $J$ Obstet Gynaecol Res 2001;27:217-20.

9. Abramov Y, Elchalal U, Schenker JG. Febrile morbidity in severe and critical ovarian hyperstimulation syndrome: A multicentre study. Hum Reprod 1998;13:3128-31.

10. Balasch J, Fabregues F, Arroyo V, et al. Treatment of severe ovarian hyperstimulation syndrome by a conservative medical approach.Acta Obstet Gynecol Scand 1996;75:662-7.

11. Fabregues F, Balasch J, Gines P, et al . Ascites and liver test abnormalities during severe ovarian hyperstimulation syndrome. Am J Gastroenterol 1999;94:994-9.

12. Abramov Y, Naparstek Y, Elchalal U, et al. Plasma immunoglobulins in patients with severe ovarian hyperstimulation syndrome. Fertil Steril 1999;71:102-5.

13. Zosmer A, Katz Z, Lancet M, et al. Adult respiratory distress syndrome complicating ovarian hyper-stimulation syndrome. Fertil Steril 1987;47:524-6.

14. Golan A, Ronel R, Herman A et al. Ovarian hyperstimulation syndrome: an update review. Obstet Gynecol Surv 1989;44:430-40. 